\title{
Trends in the Contraceptive Method Mix in Low- and Middle-Income Countries: Analysis Using a New "Average Deviation" Measure
}

\author{
John Ross, ${ }^{a}$ Jill Keesbury, ${ }^{b}$ Karen Hardee ${ }^{b}$
}

Applying a standard measure of the method mix evenness suggests 4 patterns among 15 countries moving toward a more balanced mix: (1) rise of one previously underrepresented or new method, (2) replacement of traditional with modern methods, (3) continued but declining domination by a single method, and (4) general movement toward a balanced mix. Improving availability of underutilized or new methods can improve the method mix, although better implementation of more popular methods might increase contraceptive use more expeditiously.

\begin{abstract}
The method mix of contraceptive use is severely unbalanced in many countries, with over half of all use provided by just 1 or 2 methods. That tends to limit the range of user options and constrains the total prevalence of use, leading to unplanned pregnancies and births or abortions. Previous analyses of method mix distortions focused on countries where a single method accounted for more than half of all use (the $50 \%$ rule). We introduce a new measure that uses the average deviation (AD) of method shares around their own mean and apply that to a secondary analysis of method mix data for 8 contraceptive methods from 666 national surveys in 123 countries. A high AD value indicates a skewed method mix while a low $A D$ value indicates a more uniform pattern across methods; the values can range from 0 to 21.9. Most $A D$ values ranged from 6 to 19 , with an interquartile range of 8.6 to 12.2. Using the $A D$ measure, we identified 15 countries where the method mix has evolved from a distorted one to a better balanced one, with $A D$ values declining, on average, by $35 \%$ over time. Countries show disparate paths in method gains and losses toward a balanced mix, but 4 patterns are suggested: (1) rise of one method partially offset by changes in other methods, (2) replacement of traditional with modern methods, (3) continued but declining domination by a single method, and (4) declines in dominant methods with increases in other methods toward a balanced mix. Regions differ markedly in their method mix profiles and preferences, raising the question of whether programmatic resources are best devoted to better provision of the well-accepted methods or to deploying neglected or new ones, or to a combination of both approaches.
\end{abstract}

\section{INTRODUCTION}

I $\mathrm{t}$ has long been recognized that the availability of only 1 or 2 contraceptive methods in a country constrains total contraceptive use and limits the options that women and couples have to manage their pregnancies. Conversely, adding methods expands choice for women and men and increases contraceptive use. With renewed attention to improving access to family planning services that respect and protect human rights, including access to a fuller, more

\footnotetext{
a Futures Group, Washington, DC, USA.

${ }^{b}$ Population Council, Washington, DC, USA.

Correspondence to John Ross (rosshome8@frontiernet.net).
}

informed choice of methods, experts have considered what it means for programs to offer a full range of contraceptive methods. ${ }^{1,2}$ In some countries, governments or markets have not enabled access to certain modern methods; in other countries, some methods are inherently unpopular, as with vasectomy and the condom. In some settings, such as rural Africa, certain methods are not easily accessible because they are clinically difficult to implement, as with sterilization or the intrauterine device (IUD). Clearly, the current contraceptive method mix is severely unbalanced in many countries, with over $50 \%$ of all use by a single method or with only 2 methods accounting for most use. $^{3}$ 
Experiences with changes in the contraceptive method mix are of interest to policy makers and donors, since a broader mix expands contraceptive method choice, letting women and couples choose the method that suits them best and change methods as their circumstances and needs change. How to expand method mix remains an important programmatic question. This entails a focus mainly on the "share" of use held by each method-that is, the portion of all use, with the sum of the portions always adding to $100 \%$. A totally balanced mix, with even shares for all methods, is never a program objective since it would mean, for example, that condom use would equal that of the implant and IUD use would equal that of male sterilization. Instead, the objective is to generally move away from an obviously distorted mix, without specifying precisely how fully balanced the mix should be, while enlarging access to a wider variety of method choices. In practice, it is easier to know when a mix is seriously distorted than it is to specify the ideal mix, due not only to program limitations but also to strong social norms that may block adoption of a particular method. Over time, countries will vary in which methods gain or lose shares, while total use in most cases will increase.

Exclusive attention to the contraceptive method mix, by itself, can give misleading results, since the same mix may prevail at both low and high levels of total use. A poor method mix can exist in a low-prevalence setting, such as Nigeria, but also in China, where the contraceptive prevalence rate (CPR) is in the eighties. ${ }^{16}$ Further, a rapid change in the method mix may distort the mix but simultaneously raise the overall level of use, as with the injectable in eastern and southern Africa. In that case, a more distorted method mix has actually increased choice by making an important method more available than before. In short, an analysis of mix changes over time also requires attention to changes in levels of total contraceptive use.

This paper reviews previous work devoted to measuring distortions in the mix, and it builds on that work by analyzing trends over time in the distribution of users across 8 contraceptive methods, using data available in national surveys in low- and middle-income countries (LMICs). The paper introduces a new measure of distortions in the method mix - the "average deviation" of method shares around their own mean. This measure is used in conjunction with total contraceptive use to give a more complete and programmatically useful picture of trends over In many countries, time, along with possible programmatic responses to improving the method mix.

\section{PREVIOUS MEASURES OF METHOD MIX SKEW}

A number of studies have focused on the "skew" in the method mix. A method mix is clearly distorted, or skewed, when a single method covers more than half of all use (the $50 \%$ rule). A series of 3 analyses has applied the 50\% rule to large numbers of national surveys, ${ }^{4-6}$ and we build on this work below. The latest report found that $30 \%$ of 109 developing countries suffered from a skewed method mix, ${ }^{4}$ down from $35 \%$ in a 2006 analysis. ${ }^{6}$ Among the contraceptive methods, the injectable showed increases in use, while sterilization and the IUD showed relative declines.

Other studies have analyzed the use of specific contraceptive methods within the method mix. A United Nations (UN) report covering both developed and developing countries found that, globally, more than half of all users relied on either female sterilization or the IUD. ${ }^{3}$ Use was highly concentrated: in nearly every country, 1 or 2 methods accounted for over half of all use among married/in-union women. However, regions differed sharply in their particular method mixes. The UN found that little change occurred in the mix of methods between 1990 and 2011, either globally or within individual regions. Still, some increase occurred during that period for the injectable and some decline occurred for traditional methods. The pill had the widest geographic spread, and male methods the least; such imbalances limit easy movement between methods to adjust to personal circumstances and aims.

The increase in injectable use, noted in the UN review, has modified the method mix in eastern and southern African countries and elsewhere, as reviewed by Adetunji ${ }^{7}$ and by Sutherland et al. ${ }^{8}$ Ross and Agwanda 9 showed that the injectable Increased increase has been mainly additive to the prior level of total use, rather than substituting for other methods. While its popularity has raised total use in many settings, it is a short-acting method, and questions still remain about the frequency of its discontinuation and switching to other methods. Little is known about which methods, if any, women turn to when they discontinue use; in a review of 23 countries, Ali and Cleland ${ }^{10}$ found that among users of modern methods who discontinued, as of 3 months later, $26 \%$ were at a single contraceptive method accounts for more than $50 \%$ of all contraceptive use.

\section{The aim is not to prescribe a specific ideal method mix but to generally increase access to a wider variety of method choices.}

\section{A poor method mix can prevail at both low and high levels of contraceptive use.}


Adding more methods to the method mix tends to increase total contraceptive use.

risk of becoming pregnant (i.e., they were not using any method), $10 \%$ were pregnant, and $60 \%$ had switched to another method (median values).

When the current mix is augmented by access to an additional method, total use tends to rise. Asian examples were noted by Freedman and Berelson $^{11}$ and by Jain, ${ }^{12}$ who estimated for Taiwan that adding 1 method to the mix would increase total use by about 12 percentage points (e.g., from $30 \%$ to $42 \%$ total contraceptive prevalence). Ross and Stover ${ }^{13}$ estimated that making 1 additional method available to at least half of the population raised modern contraceptive use by 4-8 percentage points, based on 27 years of data for 113 countries.

Some of the literature on method mix has occasionally been directed to specifying method mixes that are most appropriate for different user profiles and life objectives ${ }^{14}$ or to tools that relate the individual needs of women to the characteristics of alternative contraceptive methods. ${ }^{15}$

\section{DATA AND METHODS}

The primary set of national surveys used in our analysis is a thorough compilation provided by the UN Population Division of some 700 surveys from
This analysis draws on data from 666 national surveys in 123 countries.

\section{The average deviation provides a measure of the evenness of a country's method mix and allows for comparisons across countries.} both developed and developing countries. ${ }^{16}$ After exclusions to remove surveys from developed nations, including eastern Europe, and those that lack breakdowns by individual method, 666 surveys from 123 countries were included in this analysis (Appendix 1). Most tabulations are for the most recent surveys for the 123 countries.

Regarding the latest surveys in these 123 countries, most were of 3 types: over $40 \%$ were from the Demographic and Health Surveys (DHS), about a fourth were from the Multiple Indicator Cluster Survey (MICS) series, another fourth from independent national surveys, and the rest from other sources. By region, 38\% were for sub-Saharan Africa, 18\% each for Asia and North Africa/West Asia, 21\% for Latin America, and 4\% for Central Asia. Regarding timing, $80 \%$ of surveys were conducted from 2005 onward. The percentages of surveys in each 5-year period starting in 1995 were 5\% (1995-1999), 15\% (2000-2004), and 57\% (2005-2009), with an additional 23\% between 2010 and 2012.

The surveys provide the percentage of married women using the 8 contraceptive methods (i.e., contraceptive prevalence) that together account for most use and for which data are available for most countries. "Modern" methods include male and female sterilization, the IUD, oral contraceptive pills, the injectable, the condom, and the implant. Traditional methods are composed mainly of withdrawal and rhythm, in equal parts, representing $92 \%$ of all traditional method use (average across all DHS surveys). We could have performed separate analyses on small sets of countries where other methods were used by nontrivial percentages of women, but the aim of detecting marked changes in the overall mix in most countries required attention to the 8 methods studied here.

We converted contraceptive prevalence rates provided in the surveys (with all married women as the denominator) to the percentage of use due to each contraceptive method, totaling 100\% (with users of any contraceptive method as the denominator). Changes in these latter percentages over time made up the focus of this study. Where regional or other averages (means) are given, they are unweighted, so every country receives the same importance in the averages. The patterns would be somewhat different if they were weighted by population size. Certain individual countries are selected for separate discussion, and country details appear in several tables.

\section{The Average Deviation (AD) Measure}

Countries differ in their method mixes, all falling between the possible extremes of reliance on a single method to reliance on all methods equally; moreover, mixes change over time. How large must a change be to signal an important shift? Small shifts in surveys can come from noise in the data and/or from sampling error, while very large shifts usually reflect real and important changes in behavior.

Therefore, a standard measure of the evenness of the method mix is needed, to gauge the extent of change and to compare one country or region with another. After a review of possible measures, we chose to use the "average deviation" (AD); it is the simple average of the absolute differences around the mean (average), whether positive or negative, and for our purposes is preferable to the standard deviation, which squares deviations, including those of extreme outliers.

If all 8 methods held equal shares, they would each have $12.5 \%$ of all users ( $100 \%$ divided by 8 ), and $12.5 \%$ is always the average value. In every country, the share of each method in the mix varies around that average. Almost always, the implant, male sterilization, and the condom fall below the average. Depending on the region and 
country, any of the other methods (the pill, injectable, IUD, female sterilization, or traditional methods) can rank either above or below the average, e.g., female sterilization ranks below the average in sub-Saharan Africa and the IUD ranks above the average in the Middle East.

The AD measure captures the disparity in the mix, i.e., the sum of the 8 absolute differences around the average of $12.5 \%$. The sum of those differences can range from 0 to 21.9: if every method is used equally, no differences exist and the sum is 0 , and if a single method covers all use, the differences sum to 21.9. Most $\mathrm{AD}$ values range from 6 to 19; across all surveys, the interquartile range (i.e., the middle $50 \%$ of values, between the 25th and 75th percentiles) is from 8.6 to 12.2 .

Thus, a high $\mathrm{AD}$ value indicates a skewed method mix, with dominance of a few methods, and a low $\mathrm{AD}$ value indicates a more uniform pattern across the methods. No country has a fully uniform mix with an $\mathrm{AD}$ value of 0 , and as noted above, perfectly even shares would not likely be a program objective. In some cases, a rapid movement toward a new method might be sought programmatically, disturbing a relatively even mix.

The relationship between the mix and the total CPR must be kept in mind, as a low AD can occur at any level of the CPR. For example, in Nigeria the CPR is low whereas in Peru the CPR is high, and both have low AD scores.

TABLE 1. Percentage of Countries (Latest Surveys) and of All Surveys With Method Mix Skew According to the Cutoff Level ${ }^{a}$

\begin{tabular}{lcc}
\hline & \multicolumn{2}{c}{ No. (\%) } \\
\cline { 2 - 3 } Cutoff Level & $\begin{array}{c}\text { Countries } \\
\text { (Latest Surveys) }\end{array}$ & All Surveys \\
\hline $30 \%$ & $115(94.3)$ & $609(91.4)$ \\
$40 \%$ & $68(55.7)$ & $393(59.0)$ \\
$50 \%$ & $35(27.9)$ & $225(33.8)$ \\
$60 \%$ & $22(18.0)$ & $137(20.6)$ \\
$70 \%$ & $10(8.2)$ & $62(9.3)$ \\
\hline $\begin{array}{l}\text { a The "50\% rule" is the most commonly used cutoff level, } \\
\text { indicating that a single contraceptive method accounts } \\
\text { for more than half of all contraceptive use in a given } \\
\text { country. Changing the cutoff level changes the severity } \\
\text { of the rule. }\end{array}$ \\
\hline
\end{tabular}

The AD can also be calculated for the 7 modern contraceptive methods, the ADM; however, the dynamics of changes in contraceptive method mixes depend upon the competition between modern methods and traditional methods, usually with the former partially replacing the latter, so the $\mathrm{AD}$ measure is preferred.

We also consider an alternative measure of method mix skew, since this work builds upon the publications described above that employ the " $50 \%$ rule" as the measure of the mix's imbalance, and the results are compared below with those from the $\mathrm{AD}$ measure.

\section{FINDINGS}

\section{Variations on the $50 \%$ Rule to Define Skew}

The $50 \%$ rule tells whether a single contraceptive method accounts for more than half of all use. That has been a useful measure, and it is of interest to assess how sensitive the results are to exactly $50 \%$. It is possible to vary it, to examine changes in the outlook according to the severity of the rule. If a single method must cover $60 \%$ of all use for skew to occur, fewer countries will qualify, and if the rule is $40 \%$, more will qualify.

Table 1 presents the counts according to a range of cutoff rules, from $30 \%$ to $70 \%$, first for the 123 countries using only the latest surveys, and second for all 666 surveys to encompass some of the historical experience. By the $50 \%$ rule, $28 \%$ of countries and $34 \%$ of surveys qualify as having a skewed method mix, a finding close to that of Bertrand et al., ${ }^{4}$ which is expected since the 2 sets of data contain many of the same countries. Both results suggest some improvement: the higher figures for all surveys reflect more skew in the past, which agrees with the finding by Bertrand et al. of a decline from $35 \%$ to $30 \%$ of countries that are skewed.

Under the $40 \%$ rule, the skewness counts jump to over half $(56 \%)$ of all countries and nearly three-fifths (59\%) of all surveys. In the other direction, by the $60 \%$ rule, about a fifth of countries are still skewed (18\% of countries and $21 \%$ of surveys), which still indicates major imbalance among methods. For particular countries (not shown), the rules matter: Kenya and Uganda, each with a maximum of $47 \%$ use with a single contraceptive method, would be included under the $40 \%$ rule but not under the $50 \%$ rule. Tanzania would qualify only under the $30 \%$ rule. On the other hand, some countries that qualify by the $50 \%$ rule would not qualify with the
A high average deviation value indicates a skewed method mix while a low value indicates a more uniform pattern across methods.

The $50 \%$ rule, commonly used to measure method skew, identifies countries where a single method accounts for more than half of all use.

By the $50 \%$ rule, $28 \%$ of countries have a skewed method mix. 
$61 \%$ of users rely on the pill, traditional methods, or the injectable, which represents about $25 \%$ of all married women.
$60 \%$ rule. Examples in sub-Saharan Africa are Malawi (56\%), Niger (56\%), and Rwanda (51\%), and elsewhere, Egypt (59\%) and Mexico (55\%). Regardless of the rule used to measure skew, the results show major shortfalls in making a wide variety of contraceptive choices available.

The dominant method in countries with skewed method mix (by the $50 \%$ rule) is quite different by region (Figure 1). Traditional methods stand out in sub-Saharan Africa and to a lesser extent in North Africa/West Asia, and the pill is also popular in these 2 regions. The injectable is prominent in sub-Saharan Africa as well as in Asia. The IUD is important, but 5 of its 7 countries are the 5 Central Asia Republics. Female sterilization is dominant in 2 Latin American countries and 1 Asian country. The other 3 methods (male sterilization, the implant, and the condom) do not show skew anywhere. The figure is based on 35 countries, and for each country meeting the $50 \%$ rule, there are others in the same region just below $50 \%$.

\section{Method Mix at the Global, Regional, and Country Levels}

The overall pattern of contraceptive use by method appears in Figure 2, for married/in-union women using any method across the 123 countries (all methods sum to $100 \%$ of users). Among these contraceptive users, 22\% use the pill and another $22 \%$ use traditional methods, but the levels are best understood with attention to the contraceptive prevalence among all married/in-union women by method. Those percentages are much lower, and are given along the $\mathrm{x}$-axis with the method labels. Among all users, $61 \%$ rely either on the pill,

FIGURE 1. Number of Countries With Method Mix Skew According to the 50\% Rule, ${ }^{a}$ by Dominant Method (N=35 Countries)

- sub-Saharan Africa $\quad$ North Africa/West Asia $\quad$ Latin America $\quad$ Central Asia Asia

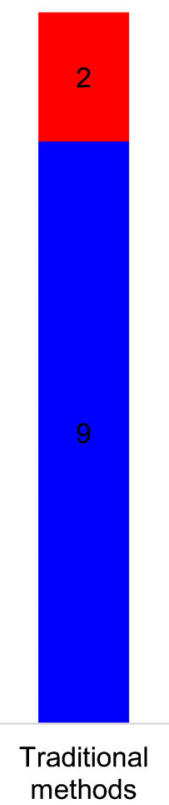

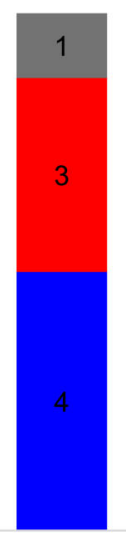

Pill
IUD

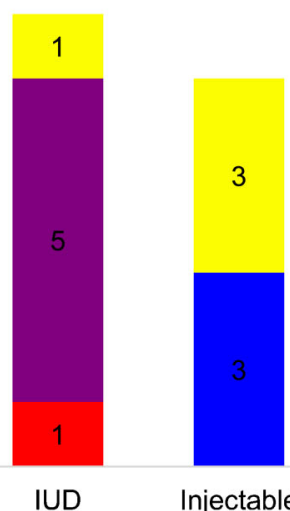

Injectable

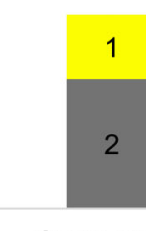

Sterilization female

\section{0} 0 0

terilization, Implant male 
FIGURE 2. Method Mix Among Contraceptive Users Based on Latest Surveys for 123 Countries

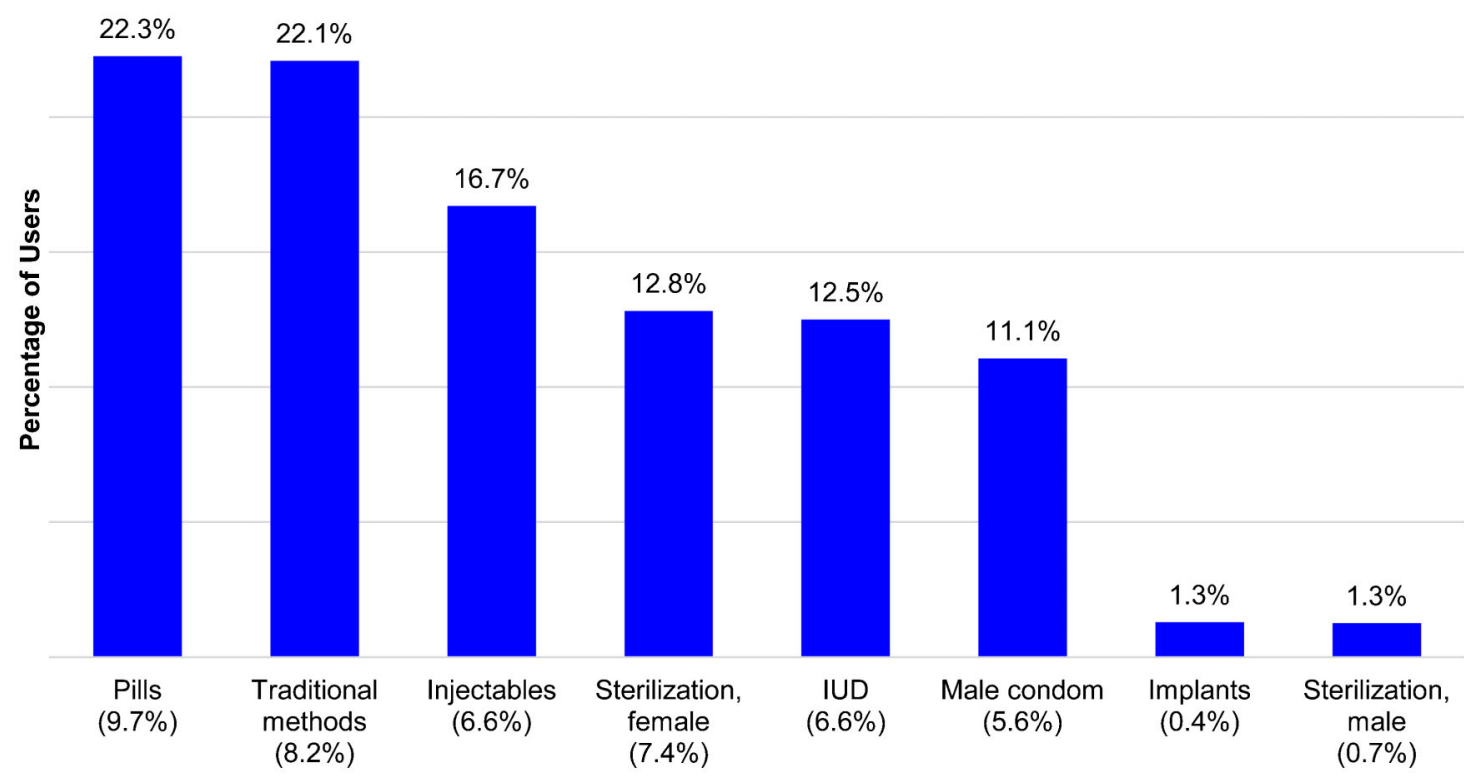

Contraceptive Method (CPR)

Abbreviation: CPR, contraceptive prevalence rate; IUD, intrauterine device.

traditional methods, or the injectable, but that represents only $24.5 \%$ of married/in-union women.

Regions differ greatly from these averages, as shown in Table 2. Many contraceptive users (lower panel) in sub-Saharan Africa rely on traditional methods while fewer do so in Central Asia, where the injectable is nearly ignored and the IUD is paramount. Male sterilization plays a minor role in each region, while female sterilization varies from $2 \%$ to $28 \%$ of users, with high values only in Latin America and Asia. The injectable ranges widely, from 2\% in Central Asia and up to one-fourth of all users in sub-Saharan Africa. The condom varies less by region, and accounts for around $11 \%$ of users overall. The implant is nearly negligible, but its use has increased recently in some countries.

The actual contraceptive prevalence appears in the upper panel of Table 2, which provides the percentage of all married/in-union women using each method. As noted, a method with a high percentage of users commonly reflects a much lower percentage of all married/in-union women.

Among individual countries (data not shown), for modern methods, the IUD is most often the dominant method, for example, in all 5 Central Asian Republics, in Viet Nam, in Egypt, and in some other Middle Eastern countries. Female sterilization ranks first in Brazil, the Dominican Republic, El Salvador, Haiti, and India. The pill is first in Bangladesh, Niger, and Zimbabwe. The injectable is first in Ethiopia, Indonesia, Malawi, and Rwanda. Vasectomy, the condom, and the implant are never the most commonly used method. Apart from modern methods, the most common maximum is for traditional methods, usually in countries with a low CPR, many of which are in sub-Saharan Africa.

\section{Method Mix by Age, Residence, and Wealth Quintiles}

The DHS set permits analysis of contraceptive use by personal characteristics, including age, residence, and wealth quintiles. The method mix changes systematically as women age (Figure 3 ). As age advances, the most notable growth is for female sterilization; its share is quite low below age 25 but then increases sharply and peaks at ages 45-49. All age groups neglect male sterilization

\footnotetext{
Method mix changes systematically as women age, with the most notable growth for female sterilization.
} 


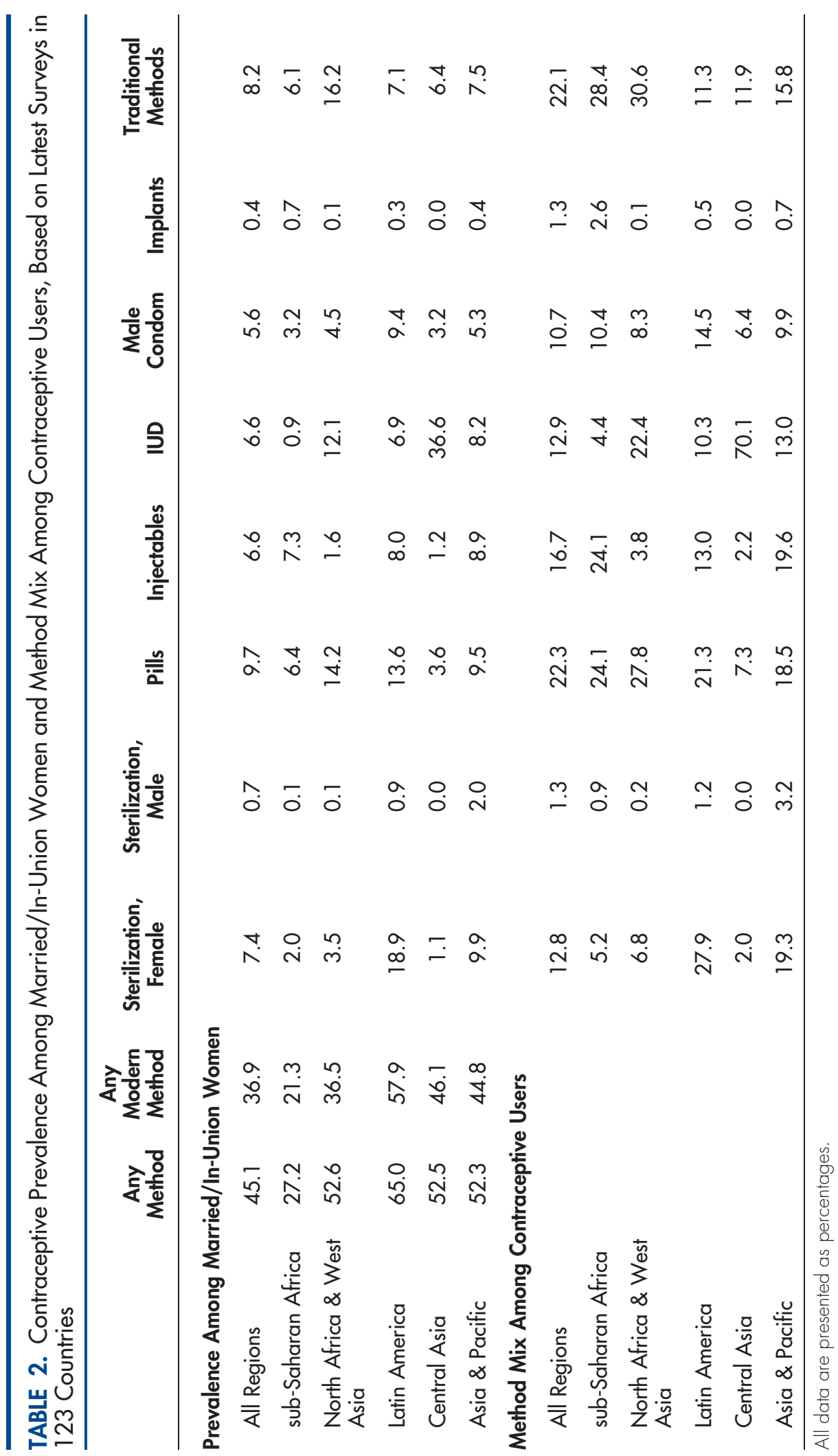




\section{FIGURE 3. Method Mix Among Contraceptive Users by Age}

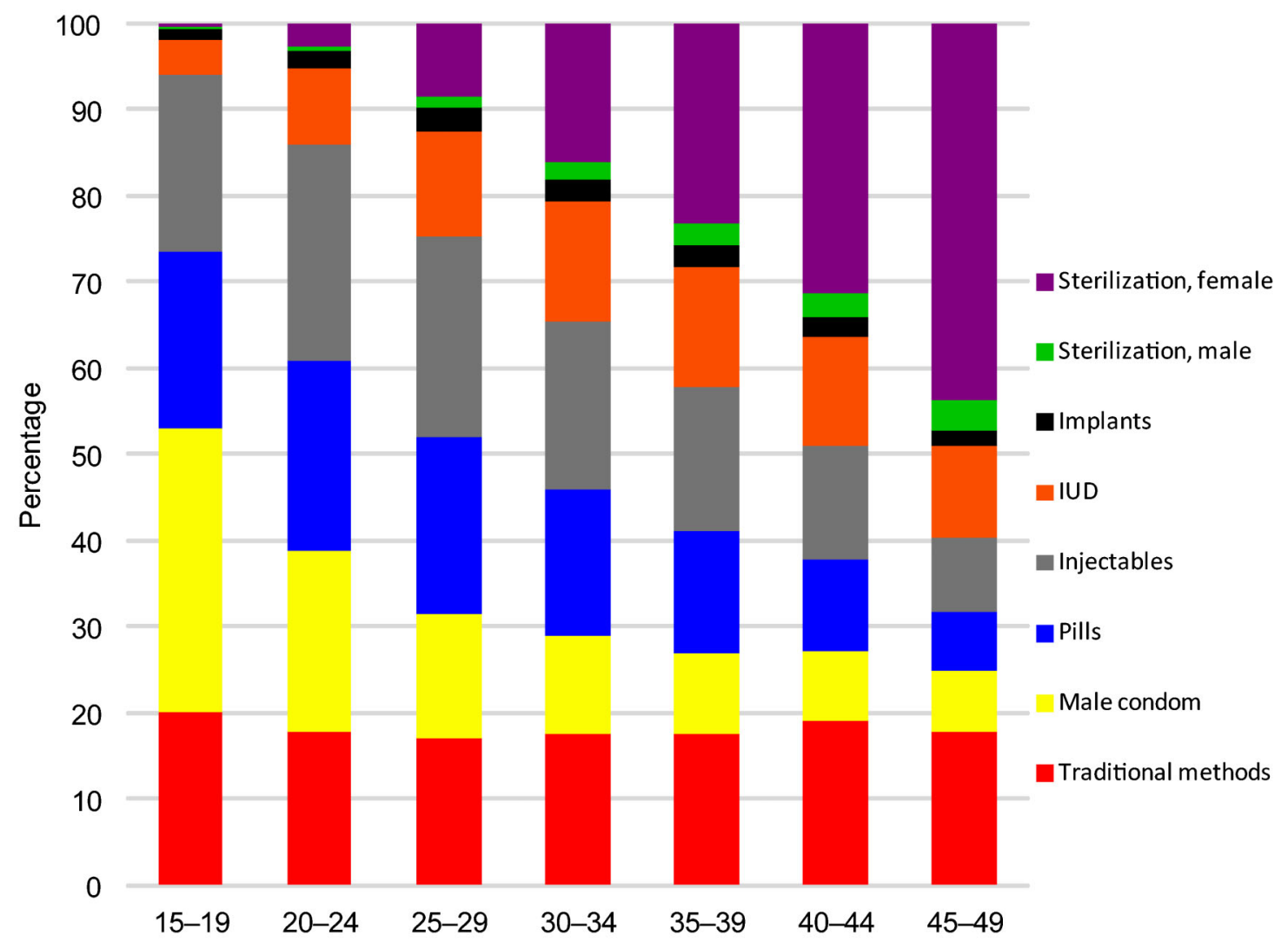

Abbreviation: IUD, intrauterine device.

and the implant. These results are for all regions merged; there is decidedly more selectivity by region and country. (For unmarried, sexually active adolescents, a clear shift occurs as youth age and gain more experience with contraceptive use. Between ages 15-19 and 20-24, reliance on the pill and injectable increases at the expense of the condom; data not shown.)

By residence, rural users show somewhat more use of traditional methods and injectables than urban users do, and less use of the condom (data not shown). However, the differences are relatively small. Total contraceptive prevalence averages $47.7 \%$ and $36.1 \%$ for urban and rural areas, respectively.

According to wealth quintiles, method shares are not greatly different (data not shown). While the quintiles differ sharply in total contraceptive prevalence (from $29.9 \%$ to $34.5 \%$ to $38.0 \%$ to $42.2 \%$ and $49.9 \%$ in sequence across the 5 quintiles), the profiles of their method preferences are basically similar. The main exception is the greater reliance on traditional methods by the bottom quintile as well as somewhat greater reliance on the injectable.

\section{Dynamics of Method Mix Changes Using the Average Deviation Measure}

The method mix in some countries has remained skewed over time, while in others it has changed substantially. Of particular interest are 15 countries with marked improvements to their method mixes, which show patterns that may suggest potential program actions for other countries wishing to adjust the mix.

To identify these illustrative countries, the $\mathrm{AD}$ values for each country were themselves 
assessed for their degree of variation and for the degree of linearity for the decline in the values. That isolated countries that had experienced a historic reduction and regular decline in skew. In more detail, first a statistical measure of variability was applied to the full series of AD values in each country. In many countries, variability was small, indicating little change over time. In others, the changes were erratic. Leaving those aside, the countries with large $\mathrm{AD}$ variability were examined to identify those with a linear pattern of decline in the values, suggesting a historic regularity in the changes. The 15 cases here represent countries where the method mix has changed considerably and fairly regularly over time, as holding the greatest interest for programmatic strategies to reduce extreme skews in the mix.

Downtrends in the $\mathrm{AD}$ values are shown in Figure 4, using the full sequence of available surveys for each country. For each line in the figure, survey number 1 represents the earliest survey conducted in that country, and each subsequent survey follows. (The dates for the data points differ among the countries and cannot be displayed separately; the time intervals also vary between surveys. See Appendix 2 for all survey dates and details on method use.) The longest series shown are 15 for Viet Nam, starting in 1988, and 13 for Egypt, starting in 1974-75.

In Figure 4, the $\mathrm{AD}$ values are highest at the left, at nearly 20 for Rwanda and Benin, for early dates when traditional methods dominated the mix and the CPRs were quite low. On the other hand, at the right, low $\mathrm{AD}$ values are shown for 3 countries clustered near the bottom, for Iran, Peru, and Colombia. In all 3 countries, traditional methods were very dominant at the start, fading steadily over the years. However, the 3 countries took quite different paths for which methods gained in the method mix share and which ones lost, as discussed below. In Iran, the pill declined in share as use of the IUD and female sterilization gained. Peru illustrates the opposite, where the IUD and female sterilization declined while the injectable and condom came into better balance with them. In Colombia, the trends were very regular

FIGURE 4. Declining Trends in Method Mix Skew Based on Average Deviation Values in 15 Selected Countries

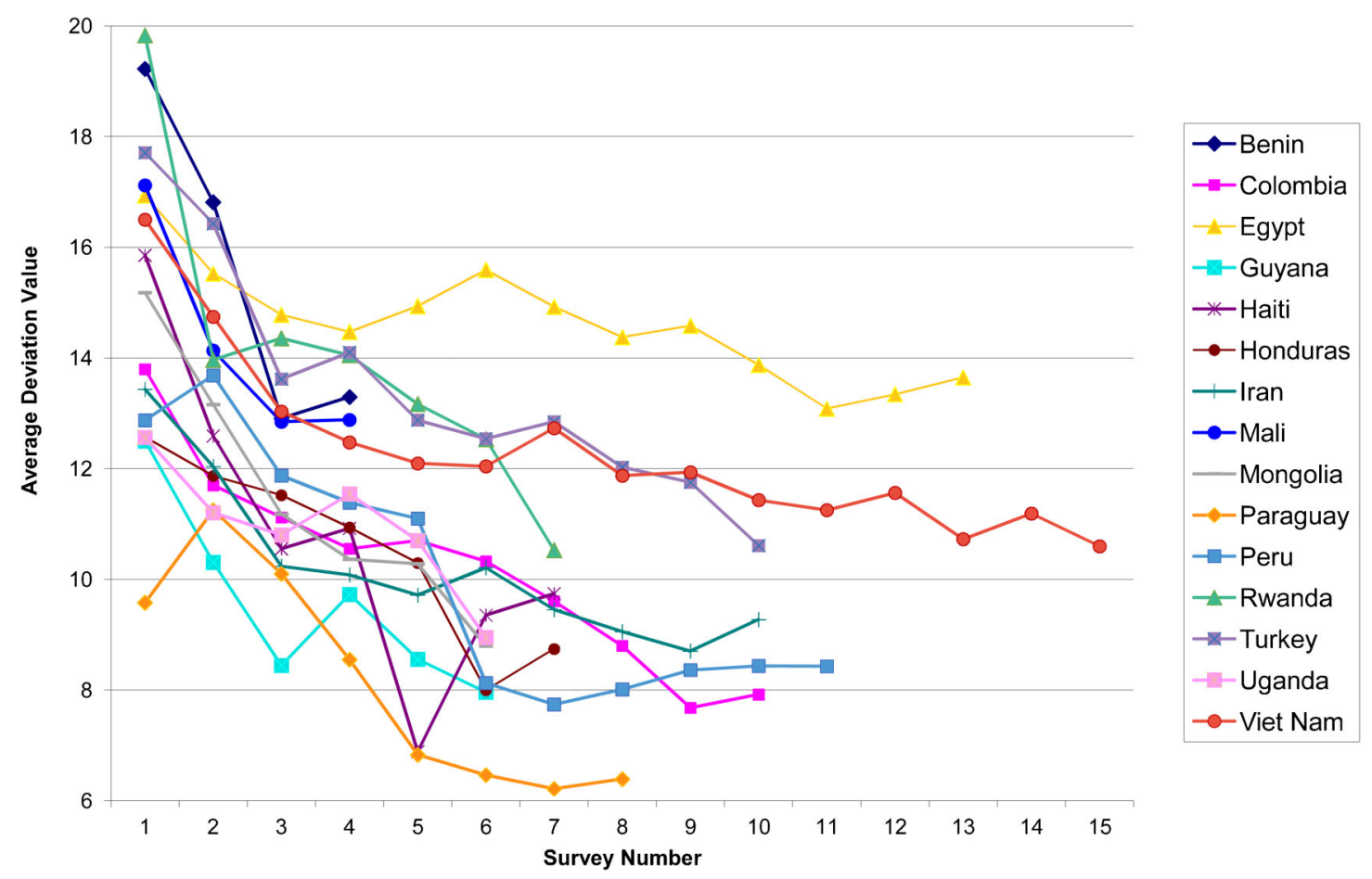


over the years, with declines from high early values for the IUD and pill, while female sterilization, the injectable, and condom gained. Note that the shares for sterilization in all countries come from adoptions during numerous past years, unlike shares for resupply methods, which reflect behavior more recently and have shares that are more sensitive to program changes year by year.

Reflecting the long-term transitions toward a more even mix in these 15 countries, the changes in the $\mathrm{AD}$ from the initial to the latest surveys have been substantial, down by 5.3 points, on average, for a $35 \%$ decline (Table 3 ).

The overall CPR levels vary considerably among these countries, since the same $\mathrm{AD}$ value can occur at either a high or a low level of overall contraceptive use. However, there is evidence that lower $\mathrm{AD}$ values, i.e., a more even mix, and higher CPRs tend to go together. When all countries (latest surveys) are divided in half by low vs. high $\mathrm{AD}$ values (above and below the median), the average CPR value is $48.9 \%$ for low-AD countries, with less skew, and only $41.0 \%$ for the high-AD countries, with more skew. This holds true within both the low and the high range of contraceptive use. Within the low range (below the median) of CPRs, countries with high ADs average a CPR of only $19.6 \%$, compared with a $23.7 \%$ CPR for countries with low ADs. Similarly, for countries in the high range of CPRs, the figures are $58.9 \%$ vs. $62.4 \%$, respectively.

These patterns are consistent with the likelihood that broadening the method mix can help lead to a higher overall level of contraceptive use, as found for 64 countries cross-classified by the variability of access among methods and the overall level of access. ${ }^{17}$ The highest CPRs were found where average access was both high and relatively even among methods.

\section{Method Gains and Losses}

The way by which the method mix changes takes many forms, and the interplay differs considerably for which methods gain and which ones lose. Table 4 summarizes the shifts in the 15 countries with marked changes to their method mixes over time, arranged by region. In most countries, women have been moving from traditional to modern contraceptive methods. The other notable trend is that the injectable, as a newer method, shows only gains, never a loss. In some countries, condoms have risen in the mix (and not necessarily in settings with high HIV/AIDS prevalence). In a few countries where one method was extremely dominant over the years, that method has lost some ground recently. In other countries, rather irregular shifts have occurred, following different paths, but the net effect has still been a steady decline in the $\mathrm{AD}$ values. Variability among the countries is the overriding tendency, as was evident also among regions.

Patterns of Movement Toward a More Balanced Method Mix

Average deviation in the method mix Notwithstanding the variability, we can take of 15 countries note of certain patterns, recognizing that these declined, on must be somewhat approximate. Four tendencies average, by emerge, each of which is illustrated below in a $\mathbf{3 5 \%}$ over time. chart for one of the countries to clarify how each

TABLE 3. Average Deviation (AD) Values for Method Mix Skew in Initial and Latest Surveys, 15 Countries

Country, Initial \& Latest Survey Year $\begin{gathered}\text { AD Value } \\ \text { in Initial } \\ \text { Survey }\end{gathered} \begin{gathered}\text { AD Value } \\ \text { in Latest } \\ \text { Survey }\end{gathered}$ Decline

sub-Saharan Africa

Benin, 1981/82 \& 2006

Mali, $1987 \& 2006$

19.2

13.3 5.9

Rwanda, 1983 \& 2010/11

17.1

12.9

Uganda, 1988/89 \& 2011

19.8

10.5

North Africa \& West Asia

Egypt, 1974/75 \& 2008

8.9

Iran, 1976/77 \& 2002

16.9

13.7

3.2

Turkey, $1963 \& 2008$

Asia

Mongolia, 1994 \& 2008

17.7

10.6

Viet Nam, 1988 \& 2010/11

\section{Latin America}

Colombia, 1969 \& 2010

16.5

10.6

Guyana, 1975 \& 2009

Haiti, 1977 \& 2005/06

12.5

8.0

Honduras, 1981 \& 2005/06

15.9

9.7

Paraguay, $1977 \& 2008$

12.6

8.7

3.9

Peru, $1969 / 70 \& 2010$

11.2

6.4

4.8

Means

12.9

8.4

4.5

15.2

9.8

5.3 
TABLE 4. Shifts in Contraceptive Method Mix by Country and Region for 15 Countries

\section{Region/Country Trends in the Method Mix}

\section{sub-Saharan Africa}

Benin The injectable and pill have risen, while sterilization, the IUD, the condom, and especially traditional methods have fallen.

Mali The injectable has risen substantially with declines in the pill and traditional methods.

Rwanda Since the disruptions of the mid-1990s, the injectable has risen to over half of all use, while traditional methods have declined correspondingly. The implant gained in the latest survey.

Uganda The injectable has risen at the expense of traditional methods, with a recent increase by the implant.

\section{North Africa \& West Asia}

Egypt The IUD rose quite remarkably to a high level, with a corresponding decline for the pill. Recently, the injectable has shown some increase.

Iran Sterilization has risen steadily; in the last survey, it lost ground to a resurgence in the pill, while traditional methods lost ground.

Turkey The extensive use of traditional methods gave way to a rise in the IUD and condom, as well as female sterilization.

\section{Asia}

Mongolia The pill, injectable, and condom have risen while the IUD and traditional methods have fallen.

Viet Nam The historic dominance of the IUD has weakened as shares of the pill and condom have gained.

\section{Latin America}

Colombia

Sterilization rose very sharply over the years, along with a small rise for condoms. Shares for the pill, IUD, and traditional methods declined.

Guyana The pill and traditional methods have lost ground, while the other methods show irregular trends that balance out to reduce skew.

Haiti The picture changed sharply from 1994/95 onward. Sterilization declined while the injectable rose, with irregularities for other methods.

Honduras The injectable share increased sharply with declines in the pill and in traditional methods.

Paraguay Shares of the injectable and condom are up while shares of the IUD and traditional methods have fallen.

Peru The IUD is down, as is sterilization slightly, while the injectable and especially the condom have risen.

mix developed over time. Because the method mix is often confused with the CPR level, the $\mathrm{X}$-axis includes the CPR for each year so any point on the curve can be translated to the percentage of all married women using the method.

Takeoff of one method partially offset by changes among other methods. The first pattern, found in 7 countries (Benin, Haiti, Honduras, Mali, Peru, Rwanda, and Uganda) is a marked rise by one contraceptive method that is partially offset by changes among the other methods. The one method starts well below the average use of $12.5 \%$, which would be its share if women were using all 8 contraceptive methods equally, and rises well above it; the overall result is less total dispersion in the shares among the methods than before, and a reduced $\mathrm{AD}$ value. The rise of the injectable is the primary example, illustrated by Uganda (Figure 5), where the rise in the injectable share is nearly a mirror image of the decline in the share of traditional methods. The pill has lost ground while the implant is up in the 


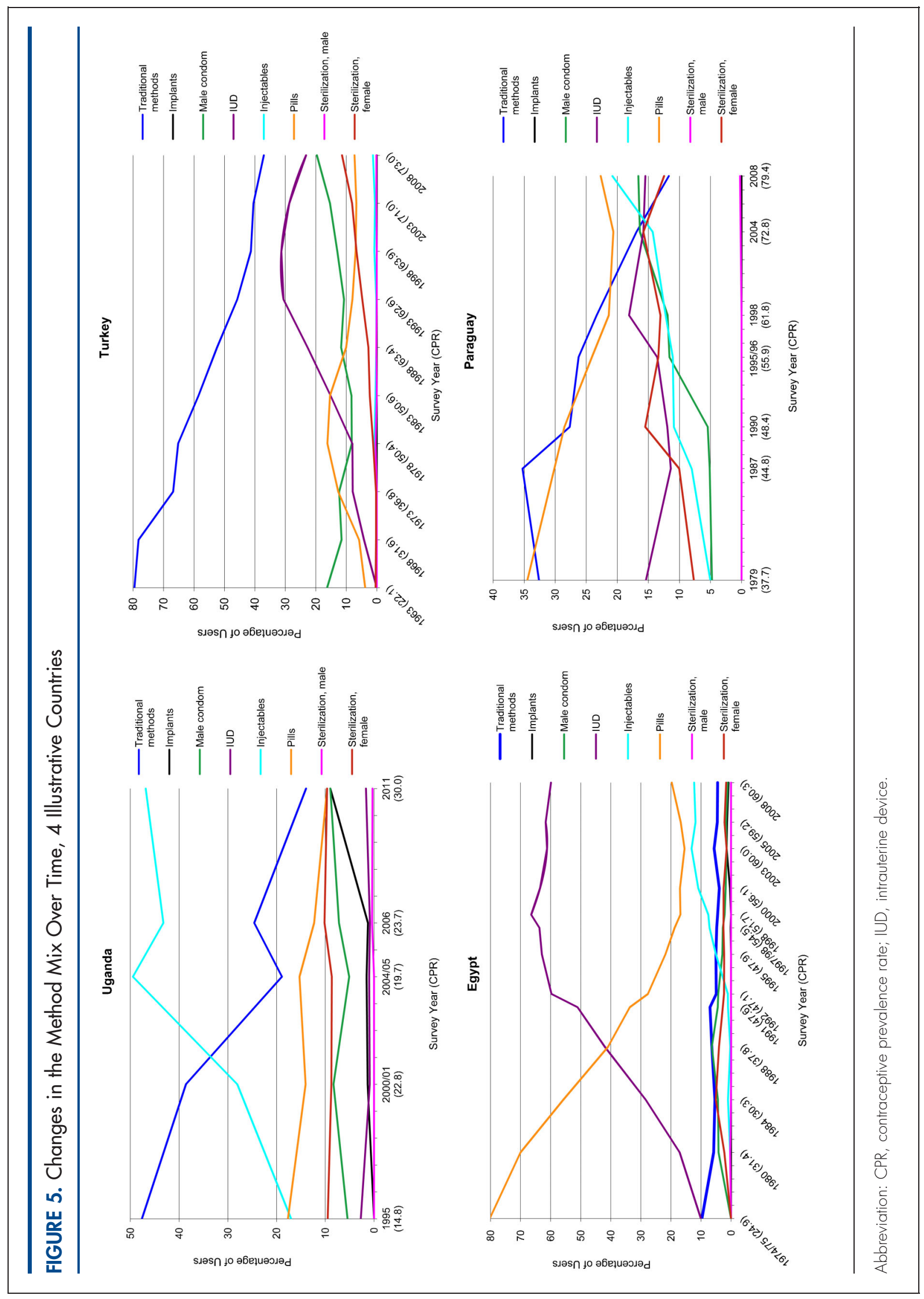




\section{Both the $50 \%$ rule and the average deviation rule are useful measures of method mix distortion.}

\section{Paraguay shows general movement from marked distortion to an unusually balanced method mix.}

latest survey. The other methods have been flat, and male sterilization has a trivial share, as it does elsewhere.

Systematic replacement of traditional methods with other methods. A second pattern is the systematic replacement of traditional method dominance by the IUD and condom. Turkey is an outstanding example; it was known for many years as the example of fairly high contraceptive prevalence based just on traditional methods, primarily withdrawal (Figure 5). The surveys, however, show a marked decline in withdrawal as modern methods replaced it, especially the IUD, with recent gains by the condom and female sterilization. Colombia is another example of nearly all methods having shares close together, except for female sterilization, the most-used method, whose high level reflects an accumulation over many years.

Continued but declining domination by a single method. A third pattern shows a single method that is both dominant and stable, with minor losses recently. This pattern is illustrated by Egypt and Viet Nam. In Egypt, the pill was the primary method at the start, with all other methods at low levels (Figure 5). However, it lost ground sharply in favor of the IUD, which rose to a stable level of three-fifths of all contraceptive use in the country. The pill plateaued at $15 \%-$ $20 \%$, while the injectable had a recent rise. The other methods are still minimal, including condoms and even traditional methods, which interestingly were never popular in Egypt. Over the 33 years shown, the CPR has risen from 25\% to $60 \%$.

Declines in dominant methods with increases in other methods toward a balanced method mix. A fourth pattern, illustrated by Paraguay, shows movement from marked distortion to an unusually balanced mix (Figure 5); it has the lowest $\mathrm{AD}$ value of 6.4 among all the countries. At the beginning of the survey period, the pill and traditional methods were highest, but by the end, all methods had similar shares except for male sterilization and the implant. The CPR in Paraguay rose from $38 \%$ in 1979 to $79 \%$ by 2008, illustrating a case of improved choice along with widespread use of all methods.

Mixed patterns. Besides the countries mentioned above, the remaining 3 of the 15 selected countries, Guyana, Iran, and Mongolia, show somewhat irregular trends that involve different sets of methods.

\section{DISCUSSION}

Previous measurements of distortions in contraceptive method mix have used the $50 \%$ rule while our new measure uses the average deviation of method shares around their own mean. Using national survey data from 123 countries, our analysis finds that both rules are useful. The $50 \%$ rule detects whether a country stands out as having a distortion in its method mix when a single method accounts for over half of all contraceptive use, while the $\mathrm{AD}$ rule is sensitive to the net change across all methods, without necessarily showing whether any one method is very dominant. Each approach has limitations covered by the other one; the 50\% rule does not provide the pattern for the nondominant methods and the $\mathrm{AD}$ rule does not tell whether a single method takes an extreme value.

In many countries, the method mix is firmly entrenched, showing little movement for a long time. However, the possibility of change can never be discounted, given the historic surprises of the emergence of the injectable in Indonesia and South Africa and then in much of eastern and southern Africa. The pill may see increased use in the future, as it is acceptable and present in a wide variety of countries. The IUD, so popular in the Middle East, has never been used extensively in sub-Saharan Africa, but a myriad of pilot projects over the years for various methods have shown that intensive efforts can elicit impressive increases in the use of neglected methods. ${ }^{18,19}$ In both sub-Saharan Africa and the Middle East, sterilization is minimal; for such a clinical method to increase its share in the method mix, a great deal of infrastructure work and training in the private or public sector is clearly necessary-a challenge in the poorest countries. However, the implant has shown small but definite gains in some African countries and will likely gain more users given increasing donor support for the method. ${ }^{20}$ Male sterilization has not won a wide following in Latin America, the Middle East, or much of Asia; also where the CPRs are already quite high, they may signal relatively little potential for a change in method mix.

The prospects for favorable changes will almost certainly involve different paths in the various settings, as they have in the past. In some, 1 or 2 methods will account for most change, and that can either improve the balance among 
methods or, while raising the CPR substantially, distort the method mix from its current state. In the longer run, new methods may emerge that gain popularity among users. In future surveys, repeated application of both the $50 \%$ rule and the $\mathrm{AD}$ measure can strengthen the monitoring of these developments and extend the time series, at very little effort.

Historically, it is likely that in the early days of experience with modern contraceptives, traditional methods held center stage in the method mix since they were the only ones known in the culture, including some abstinence and deliberate extensions of breastfeeding. As modern methods became better known and total contraceptive prevalence rose, the method mix moved toward a better spread among methods but in quite different ways. In each country, the public was experimenting and gaining experience with alternative choices. At the same time, a net reduction in unmet need for family planning occurred over time in many countries, as the rise in contraceptive use outpaced declines in the desired family size.

Regarding total contraceptive prevalence, few countries have CPRs in the seventies without a substantial share of sterilization in the mix, and even those countries with extensive IUD use have generally risen to CPRs only in the mid-sixties. In developing countries, total fertility rates are usually at replacement level only in those countries with considerable use of sterilization. Interesting exceptions are Viet Nam and Turkey, which rely on a combination of the IUD and traditional methods, with extensive use of abortion in Viet Nam and perhaps in Turkey as well. ${ }^{21}$ Use of short-acting methods comes with high discontinuation rates, constraining total contraceptive use and the fertility effects.

How can both the method mix and the total contraceptive prevalence be improved? When we say that the method mix should be improved, we are really saying that some of the less-favored methods should be made more available and attractive and that promising new methods should be introduced. This would meet the needs of more women and couples, it would put the mix into better balance, and it would raise overall contraceptive use. However, there are questions of strategy. Apart from the usual counsel to "try harder" to improve accessibility and quality, with better training and supervision, and an expansion of services to the private sector, efforts to improve the method mix would focus on making the neglected methods in each country more available and on introducing new methods where feasible. However, the CPR itself may rise faster under a different strategy, posing the question of whether better implementation of the popular methods may prove more costeffective than efforts to advance methods that so far have won little response. Where the public in a country clearly dislikes a method and the national authorities neglect it, as with male sterilization in most countries, the condom in many, and the IUD in some, it may be a better strategy to improve access to and quality for the established methods, both to enhance actual choice and to raise the CPR level. The answer to such questions will vary; sometimes a relatively new method shows promise, as the injectable clearly did and as the implant currently does in some countries. That points to a policy favoring a combination of improved implementation of established methods together with attention to neglected ones and to promising new ones. Whatever the strategy, it should embrace measures to advance free and informed choice.

Both the mix and the CPR may be improved through at least 2 basic approaches. The first is for special attention to go to the large market of discontinuers from resupply methods, both to prolong use for some users ${ }^{22}$ and to offer ready alternatives for others. Very large numbers of injectable users are discontinuing use throughout eastern and southern Africa, by simply not showing up for the next shot. With proper counseling at the point-of-service, they can be encouraged toward a longer trial of the method or toward adopting alternative methods promptly after discontinuing their current method.

The second approach to improving both the mix and the CPR is the strategic focus on postabortion and postpartum women. The leverage in that focus is not generally recognized; it automatically separates out the relevant segment of the whole population as it moves through its next pregnancy experience. Apart from first births, most women who will ever have a next pregnancy or birth will do so within the next 5 years, and during that period many or most will encounter the various services related to pregnancy, birth, and child care. A more determined and disciplined focus on those programs would in many settings enlarge choice, meet women's needs faster, improve the balance of methods in the mix, and raise the CPR.

\section{Few countries have high contraceptive prevalence rates without a substantial share of sterilization in the mix.}


Survey findings of the kind reported here need to be augmented by local studies to investigate reasons why certain methods experience a takeoff. Central program initiatives always interact with public preferences and private-sector initiatives. Lessons from such studies can be drawn from cases like Uganda's, where the injectable has replaced traditional methods and where other methods, including the implant, now claim larger shares. A different type is that of Egypt, in which the IUD has proven popular, as it has elsewhere in the Middle East. Egypt illustrates the case of a strong private medical sector, which may also have had a role in the recent increase of the injectable. In neither region has sterilization been substantial. In sub-Saharan Africa the IUD has also been quite minor, and the availability of longacting methods remains very problematic.

Supply and demand factors drive both method availability and method use. Such factors include policy and programmatic changes undertaken by the public sector, but they can also include widespread changes in social norms, economies, and the growing availability (and popularity) of private-sector health care services. A more detailed historical analysis of the conditions surrounding these changes can be instructive to enhance the understanding of what mediates these transitions and the extent to which they are replicable in other countries.

Acknowledgments: We are grateful for helpful comments from 4 anonymous reviewers, and we thank Jane Bertrand for detailed suggestions. Funding for this article was provided under the USAIDfunded Evidence Project, implemented by the Population Council and partners (AID-OAA-A-13-00087).

Competing Interests: None declared.

\section{REFERENCES}

1. Center for Reproductive Rights (CRR). Gaining ground: a tool for advancing reproductive rights law reform. New York: CRR; 2006. Available from: http://reproductiverights.org/document/gainingground-a-tool-for-advancing-reproductive-rights-law-reform

2. Hardee K, Kumar J, Newman K, Bakamiian L, Harris S, Rodríguez $M$, et al. Voluntary, human rights-based family planning: a conceptual framework. Stud Fam Plann. 2014;45(1):1-18. CrossRef. Medline

3. United Nations, Department of Economic and Social Affairs, Population Division. Trends in contraceptive methods used worldwide. [New York]: The Division; 2013. Available from: http://www.un.org/en/development/desa/population/ publications/pdf/popfacts/PopFacts_2013-9_new.pdf

4. Bertrand JT, Sullivan TM, Knowles EA, Zeeshan MF, Shelton JD. Contraceptive method skew and shifts in method mix in low- and middle-income countries. Int Perspect Sex Reprod Health. 2014;40(03):144-153. CrossRef. Medline
5. Seiber EE, Bertrand JT, Sullivan TM. Changes in contraceptive method mix in developing countries. Int Fam Plan Perspect. 2007;33(03):117-123. CrossRef. Medline

6. Sullivan TM, Bertrand JT, Rice J, Shelton JD. Skewed contraceptive method mix: why it happens, why it matters. J Biosoc Sci. 2006;38(04):501-521. CrossRef. Medline

7. Adetunii JA. Rising popularity of injectable contraceptives in sub-Saharan Africa. Etude Popul Afr [Afr Popul Stud]. $2011 ; 25(2): 587-604$. CrossRef

8. Sutherland EG, Otterness C, Janowitz B. What happens to contraceptive use after injectables are introduced? An analysis of 13 countries, Int Perspect Sex Reprod Health. 2011;37(4):202208. CrossRef. Medline

9. Ross JA, Agwanda AT. Increased use of injectable contraception in Sub-Saharan Africa. Afr J Reprod Health. 2012;16(4):68-80. CrossRef. Medline

10. Ali MM, Cleland J. Contraceptive switching after method-related discontinuation: levels and differentials. Stud Fam Plann. 2010;41(2):129-133. CrossRef. Medline

11. Freedman $R$, Berelson $B$. The record of family planning programs. Stud Fam Plann. 1976;7(1):1-40. CrossRef. Medline

12. Jain AK. Fertility reduction and the quality of family planning services. Stud Fam Plann. 1989;20(1):1-16. CrossRef. Medline

13. Ross J, Stover J. Use of modern contraception increases when more methods become available: analysis of evidence from 1982-2009. Glob Health Sci Pract. 2013;1(2):203-212. CrossRef. Medline

14. Choe MK, Bulatao RA. Defining an appropriate contraceptive method mix to meet fertility preferences. Presented at: 1992 Annual Meeting of the Population Association of America; 1992 Apr 30-May 2; Denver, CO. Abstract available from: http:// www.popline.org/node/323809

15. Galway K, Stover J. Determining an appropriate contraceptive method mix. In: Futures Group. OPTIONS for Population Policy. Policy and programmatic use of DHS data: a tool for family planning program managers and analysts. Washington (DC): Futures Group; 1995. Available from: http://pubs.futuresgroup. com/PolProgDHS.pdf

16. United Nations, Department of Economic and Social Affairs, Population Division. World contraceptive use 2014. New York: The Division; 2014. Available from: http://www.un.org/en/ development/desa/population/publications/dataset/ contraception/wcu2014.shtml

17. Ross J, Hardee K. Access to contraceptive methods and prevalence of use. J Biosoc Sci. 2013;45(06):761-778. CrossRef. Medline

18. Duvall S, Thurston S, Weinberger M, Nuccio O, Fuchs-Montgomery $\mathrm{N}$. Scaling up delivery of contraceptive implants in sub-Saharan Africa: operational experiences of Marie Stopes International. Glob Health Sci Pract. 2014;2(1):72-92. CrossRef. Medline

19. Hubacher D, Akora V, Masaba R, Chen M, Veena V. Introduction of the levonorgestrel intrauterine system in Kenya through mobile outreach: review of service statistics and provider perspectives. Glob Health Sci Pract. 2014;2(1):47-54. CrossRef. Medline

20. FamilyPlanning2020 (FP2020). Implant Access Program: expanding family planning options for women. Washington (DC): FP2020; 2014. Available from: http://www. familyplanning2020.org/images/content/documents/Implant_ Access_Program_Two-Pager_June_2014.pdf

21. Henshaw SK, Singh S, Haas T. Recent trends in abortion rates worldwide. Int Fam Plan Perspect. 1999;25(1):44-48. CrossRef

22. Jain AK, Obare F, RamaRao S, Askew I. Reducing unmet need by supporting women with met need. Int Perspect Sex Reprod Health. 2013;39(03):133-141. CrossRef. Medline 


\section{Peer Reviewed}

Received: 2014 Nov 9; Accepted: 2015 Jan 20; First published online: 2015 Feb 25

Cite this article as: Ross J, Keesbury J, Hardee K. Trends in the contraceptive method mix in low- and middle-income countries: analysis using a new "average deviation" measure. Glob Health Sci Pract. 2015;3(1):34-55. http://dx.doi.org/10.9745/GHSP-D-14-00199.

(c) Ross et al. This is an open-access article distributed under the terms of the Creative Commons Attribution License, which permits unrestricted use, distribution, and reproduction in any medium, provided the original author and source are properly cited. To view a copy of the license, visit http://creativecommons.org/licenses/by/3.0/. When linking to this article, please use the following permanent link: http://dx.doi.org/10.9745/ GHSP-D-14-00199. 
APPENDIX 1. 123 Countries Included in the "Average Deviation" Method Mix Analysis, by Region

\begin{tabular}{|c|c|}
\hline Country & Latest Survey Year \\
\hline \multicolumn{2}{|l|}{ sub-Saharan Africa } \\
\hline Angola & 2001 \\
\hline Benin & 2006 \\
\hline Burkina Faso & $2010 / 11$ \\
\hline Burundi & $2010 / 11$ \\
\hline Cameroon & 2011 \\
\hline Cape Verde & 2005 \\
\hline Central African Republic & 2006 \\
\hline Chad & 2004 \\
\hline Comoros & 2000 \\
\hline Congo & $2011 / 12$ \\
\hline Congo, Democratic Republic of & 2010 \\
\hline Côte d'Ivoire & 2006 \\
\hline Dïbouti & 2006 \\
\hline Equatorial Guinea & 2000 \\
\hline Eritrea & 2002 \\
\hline Ethiopia & $2010 / 11$ \\
\hline Gabon & 2000 \\
\hline Gambia & 2001 \\
\hline Ghana & 2008 \\
\hline Guinea & 2005 \\
\hline Guinea-Bissau & 2006 \\
\hline Kenya & $2008 / 09$ \\
\hline Lesotho & $2009 / 10$ \\
\hline Liberia & 2007 \\
\hline Madagascar & $2008 / 09$ \\
\hline Malawi & 2010 \\
\hline Mali & 2006 \\
\hline Mauritania & 2007 \\
\hline Mauritius & 2002 \\
\hline Mozambique & 2011 \\
\hline Namibia & $2006 / 07$ \\
\hline Niger & 2006 \\
\hline Nigeria & 2011 \\
\hline Rwanda & $2010 / 11$ \\
\hline Sao Tome and Principe & $2008 / 09$ \\
\hline Senegal & $2010 / 11$ \\
\hline Sierra Leone & 2008 \\
\hline Somalia & 2006 \\
\hline South Africa & $2003 / 04$ \\
\hline South Sudan & 2006 \\
\hline Sudan & 2010 \\
\hline
\end{tabular}

\begin{tabular}{|c|c|}
\hline \multicolumn{2}{|c|}{ APPENDIX 1 (continued). } \\
\hline Country & Latest Survey Year \\
\hline Swaziland & 2010 \\
\hline Tanzania & $2009 / 10$ \\
\hline Togo & 2006 \\
\hline Uganda & 2011 \\
\hline Zambia & 2007 \\
\hline Zimbabwe & $2010 / 11$ \\
\hline \multicolumn{2}{|c|}{ North Africa \& West Asia } \\
\hline Algeria & 2006 \\
\hline Armenia & 2010 \\
\hline Azerbaijan & 2006 \\
\hline Bahrain & 1995 \\
\hline Egypt & 2008 \\
\hline Georgia & 2005 \\
\hline Iran & 2002 \\
\hline Iraq & 2011 \\
\hline Jordan & 2009 \\
\hline Kuwait & 1999 \\
\hline Lebanon & 1996 \\
\hline Libya & 1995 \\
\hline Morocco & 2003/04 \\
\hline Oman & 2000 \\
\hline Qatar & 1998 \\
\hline Saudi Arabia & 1996 \\
\hline Syria & 2006 \\
\hline Tunisia & 2006 \\
\hline Turkey & 2008 \\
\hline United Arab Emirates & 1995 \\
\hline Yemen & 2006 \\
\hline \multicolumn{2}{|l|}{ Latin America } \\
\hline Argentina & $2004 / 05$ \\
\hline Belize & 2006 \\
\hline Bolivia & 2008 \\
\hline Brazil & 2006 \\
\hline Chile & 2006 \\
\hline Colombia & 2010 \\
\hline Costa Rica & 2010 \\
\hline Cuba & 2006 \\
\hline Dominican Republic & 2007 \\
\hline Ecuador & 2004 \\
\hline El Salvador & 2008 \\
\hline Guatemala & 2002 \\
\hline Guyana & 2009 \\
\hline Haiti & $2005 / 06$ \\
\hline Honduras & $2005 / 06$ \\
\hline
\end{tabular}


APPENDIX 1 (continued).

\begin{tabular}{|c|c|}
\hline Country & Latest Survey Year \\
\hline Jamaica & $2002 / 03$ \\
\hline Mexico & 2006 \\
\hline Nicaragua & 2006/07 \\
\hline Panama & 2009 \\
\hline Paraguay & 2008 \\
\hline Peru & 2010 \\
\hline Puerto Rico & 2002 \\
\hline Suriname & 2006 \\
\hline Trinidad and Tobago & 2006 \\
\hline Uruguay & 2004 \\
\hline Venezuela & 1998 \\
\hline Central Asia & 1998 \\
\hline Kazakhstan & 2006 \\
\hline Kyrgyzstan & $2005 / 06$ \\
\hline Taiikistan & 2007 \\
\hline Turkmenistan & 2000 \\
\hline Uzbekistan & 2006 \\
\hline \multicolumn{2}{|l|}{ Asia \& Pacific } \\
\hline Afghanistan & 2010 \\
\hline Bangladesh & $2011 / 12$ \\
\hline Bhutan & 2010 \\
\hline Cambodia & $2010 / 11$ \\
\hline China & 2006 \\
\hline Hong Kong & 2007 \\
\hline India & $2007 / 08$ \\
\hline Indonesia & 2007 \\
\hline Korea, Republic of & 2009 \\
\hline Lao People's Democratic Republic & 2005 \\
\hline Malaysia & 2004 \\
\hline Maldives & 2009 \\
\hline Mongolia & 2008 \\
\hline Myanmar & $2009 / 10$ \\
\hline Nepal & 2011 \\
\hline Pakistan & $2012 / 13$ \\
\hline Papua New Guinea & 1996 \\
\hline Philippines & 2011 \\
\hline Singapore & 1997 \\
\hline Solomon Islands & 2006/07 \\
\hline Sri Lanka & 2006/07 \\
\hline Thailand & 2009 \\
\hline Timor-Leste & $2009 / 10$ \\
\hline Viet Nam & $2010 / 11$ \\
\hline
\end{tabular}




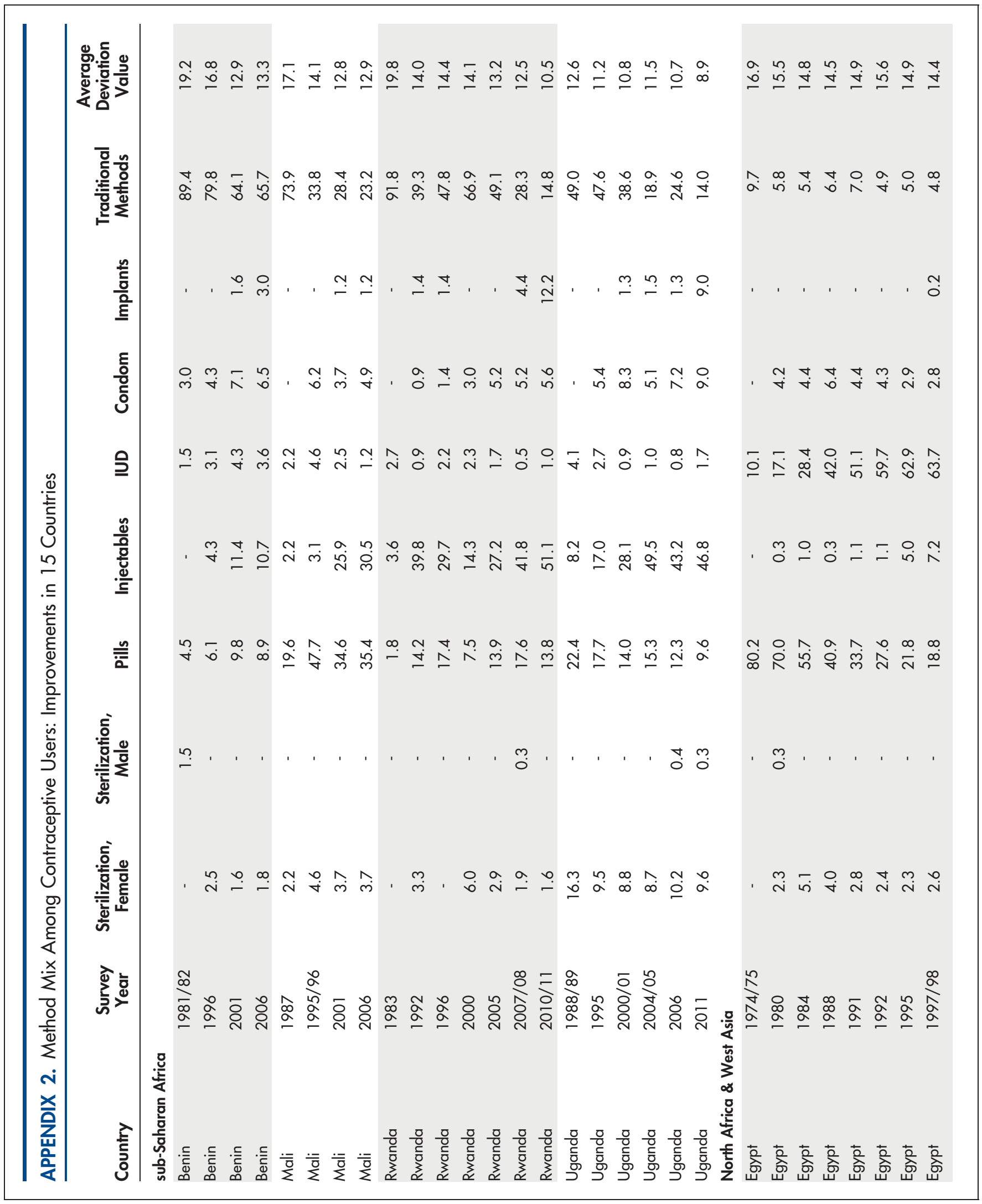




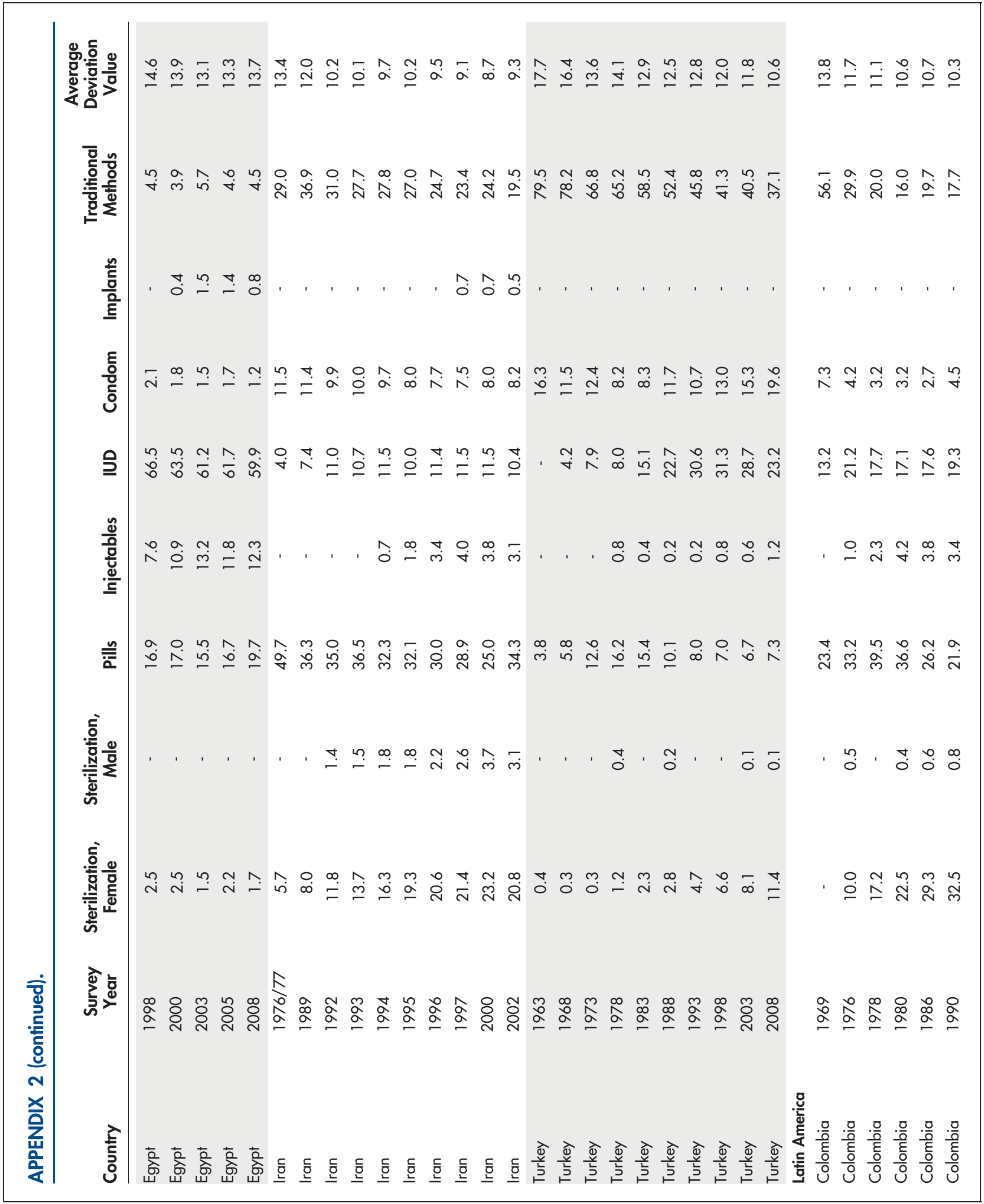




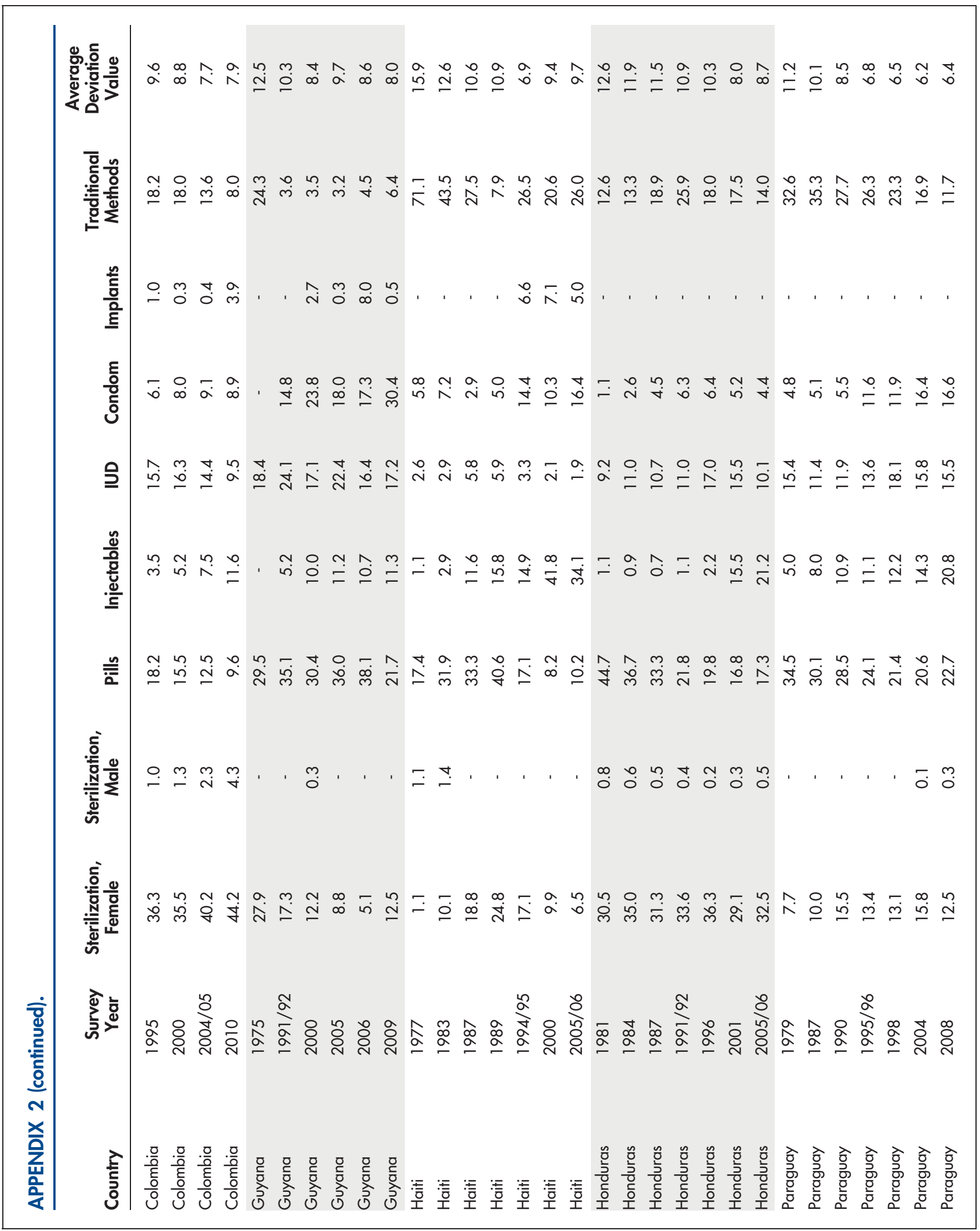




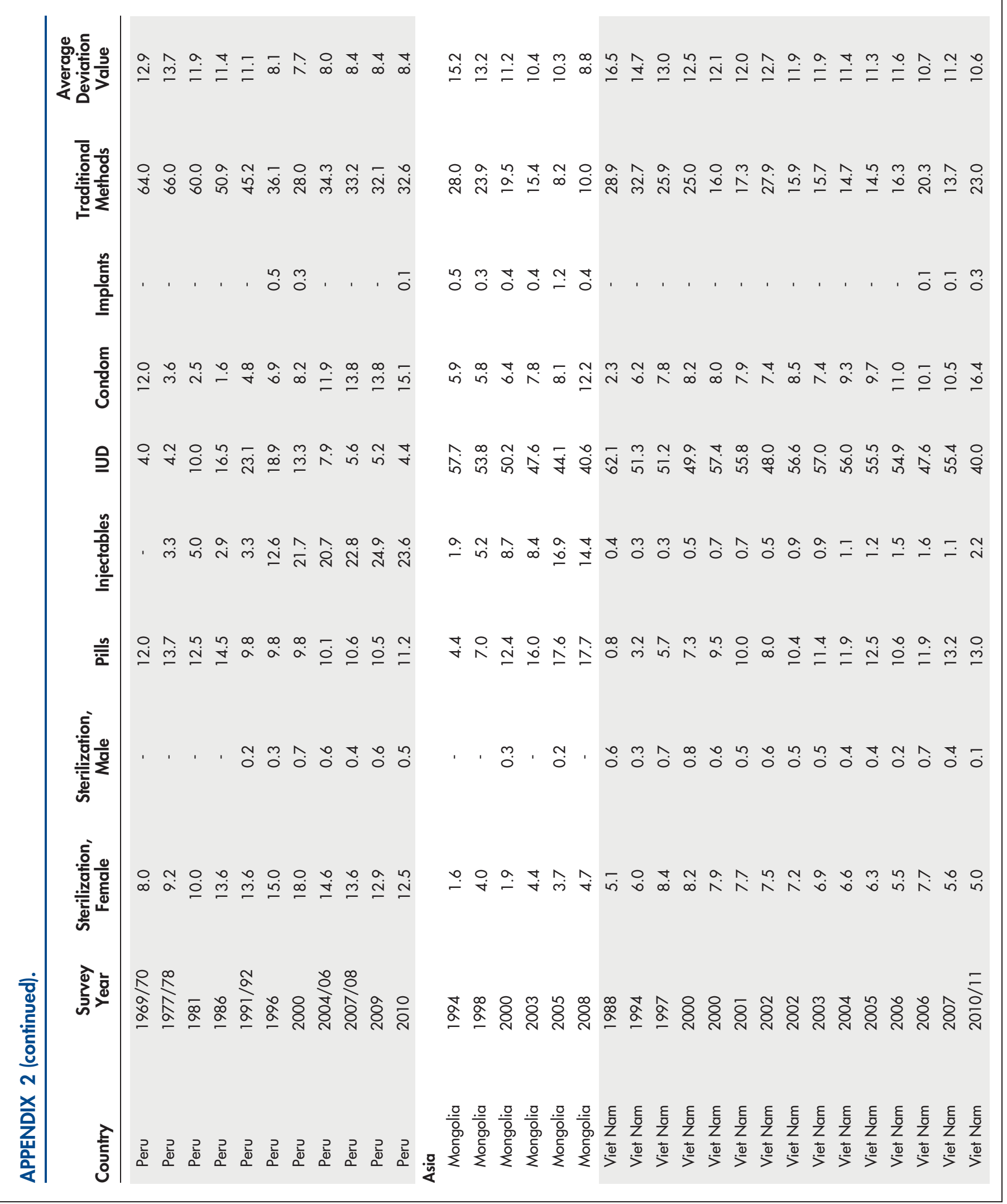

